\title{
Adenylyl Cyclases in Mycobacteria
}

\author{
Han-Seung Jeon ${ }^{1}$, In-Jeong $\mathrm{Ko}^{2}$ and Jeong-\| Oh${ }^{1}$ * \\ ${ }^{1}$ Department of Microbiology, Pusan National University, 609-735 Busan, Korea \\ ${ }^{2}$ Korea Science Academy of KAIST, 614-822 Busan, Korea
}

Received February 17, 2011/Accepted March 20, 2011

\begin{abstract}
Adenylyl cyclase (AC) catalyzes the formation of cyclic AMP (cAMP) from ATP. The cAMP produced by $\mathrm{AC}$ serves as a secondary messenger in a variety of signal transduction pathways, and controls various cellular functions in many organisms. ACs can be grouped into six classes based on their primary amino acid sequences. Eukaryotes and mycobacteria contain only members of class III AC. The catalytic cyclase domains of class III AC are active as dimers: mammalian ACs, which are composed of a single polypeptide with two catalytic cyclase domains, form the active site as a result of intramolecular dimerization of the catalytic cyclase domains. In contrast, mycobacterial ACs function as homodimers, since their polypeptides contain a single catalytic cyclase domain. Six amino acids are required for the catalytic activity of class III AC - two aspartate residues, a lysine-aspartate pair and an arginine-asparagine pair. 16 ACs belonging to the class III were identified in Mycobacterium tuberculosis H37Rv, and their characteristics are reviewed.
\end{abstract}

Key words : Adenylyl cyclase, cAMP, Mycobacterium tuberculosis, secondary messenger, signal transduction pathway

\section{서 론}

병원균을 포함하여 생물체가 환경 내에서 효율적으로 생존 하기 위해서는 외부의 환경을 인지하고 반응하여 변화된 환경 에 효율적으로 적응을 해야한다. 이 과정은 신호전달경로 (signal transduction pathway)를 통해서 이루어지며, 신호전 달경로는 신호인지(signal reception), 신호전달(signal transduction), 그리고 반응(response)의 세가지 과정으로 이루어진 다. 신호인지는 빛과 같은 물리적 신호와 화학적 신호분자 (ligand)에 특이적으로 결합하는 수용체(receptor)에 의해 이 루어지는데 대부분의 수용체는 세포막에 위치하여 외부의 신 호를 인지한다. 많은 신호분자(1차신호)들은 세포막을 자유롭 게 통과하지 못하기 때문에 신호를 세포 내부의 신호전달 관 련 분자(kinase, transcription factor, ion channel 등)에 직접 전달해줄 수가 없다. 신호전달경로에서 외부의 신호를 받아 세포 내부의 신호전달 관련 분자의 활성을 조절하는 기능을 하는 작은 분자를 이차전달자(secondary messenger)라 한다. 이차전달자로 기능을 하는 대표적인 분자는 $3^{\prime}, 5^{\prime}-\mathrm{cyclic} \mathrm{ad}^{-}$ enosine monophosphate (cAMP)로 adenylyl cyclase (AC)에 의해서 ATP로부터 합성된다[4,36].

$\mathrm{AC}$ 는 반응을 촉매하는데 있어서 금속이온 의존적인 방식 으로 $\mathrm{cAMP}$ 를 합성한다. $\mathrm{AC}$ 는 아미노산 서열을 바탕으로 총 6 개의 class (I-VI)로 분류될 수 있다[6,35]. 이 중 mycobacteria

*Corresponding author

Tel : +82-51-510-2593, Fax : +82-51-514-1778

E-mail : joh@pusan.ac.kr
에 존재하는 $\mathrm{AC}$ 들은 진핵생물에서 발견되는 $\mathrm{AC}$ 와 단백질 1 차구조가 비슷한 class III로 분류된다[35,36].

현재까지 mycobacteria의 AC 유전자는 Mycobacterium avium에서 12 개, M. leprae에서 4개, M. marinum에서 31개, M. smegmatis에서 10개, M. tuberculosis에서 16 개가 밝혀졌 다[35]. 본 총설은 결핵균을 포함하는 mycobacteria에서 발 견되는 $\mathrm{AC}$ 에 대해 지금까지 보고된 내용과 최근에 제시된 $\mathrm{CAMP}$ 와 결핵균의 숙주 내의 감염과 생존 기전과의 관계에 대해 다룰 것이다.

\section{Adenylyl cyclase 분류}

$\mathrm{AC}$ 는 촉매 도메인(catalytic domain)의 1차구조를 바탕으 로 최근까지 총 6 개 class로 분류가 되었고 서로 다른 class에 속하는 $\mathrm{AC}$ 간에는 단백질 1 차구조의 유사성이 없다. Class $\mathrm{III}$ 에 속하는 $\mathrm{AC}$ 는 고등식물을 제외한 진핵생물과 원핵생물 모두에서 발견되는 일반적인 형태의 $\mathrm{AC}$ 이고, 나머지 5 class 에 속하는 $\mathrm{AC}$ 는 일부의 세균에서만 발견된다.

\section{Class I}

$\mathrm{AC}$ 로는 처음으로 발견된 class I AC (enterobacterial $\mathrm{AC}$ ) 는 Escherichia coli, Salmonella typhimurium, Erwinia chrysanthemi, Proteus mirabilis, Yersinia pestis 등과 같은 장내세균과 Aeromonas hydrophila, Haemophilus influenzae, Pasteurella multocida, Vibrio cholerae에서 발견되었다[6]. 이들은 분해대사물 억제(catabolite repression)나 병원성(virulence) 발현과 같은 
과정에 관여한다[7]. 그 중 E. coli의 $\mathrm{AC}$ 는 아미노말단에 촉매 도메인이, 카복실말단에는 조절 도메인(regulatory domain)으 로 구성되어 있는 분자량 $97 \mathrm{kDa}$ 인 monomer 형태를 하고 있다. E. coli의 $\mathrm{AC}$ 는 cyaA 유전자에 인코딩되어 있는데, $\mathrm{glu}^{-}$ cose가 고갈되면 활성화된다. Class I AC의 3차원 구조는 아직 까지 밝혀지지 않았다[6,31].

\section{Class ॥}

Class II AC는 Bacillus anthracis와 Bordetella pertussis와 같은 병원균에서 외부로 분비되는 외독소(exotoxin)로서 기능을 한 다[5,21,28]. 이 효소가 숙주세포에 들어가게 되면, 숙주의 calmodulin에 의해 활성화되어, cAMP를 대량생산하게 되고 숙주세포의 신호전달 경로가 교란되어 질병이 유발된다. 이 $\mathrm{AC}$ 의 calmodulin-결합 도메인은 $\mathrm{AC}$ 의 활성부위에 기질이 결 합하는 것을 방해하는 기능을 한다. Calmodulin이 calmodulin-결합 도메인에 결합하게 되면 단백질의 모양 (conformation)이 변하여 활성부위가 기질의 접근에 자유로와 져 효소가 활성화된다. Pseudomonas aeruginosa에서도 class II 에 속하는 $\mathrm{AC}$ 가 발견되는데[42], 이 $\mathrm{AC}$ 는 활성자(activator)로 서 calmodulin대신 숙주세포의 세포질에 존재하는 다른 인자 를 사용한다고 알려져 있다[28].

\section{Class III}

\section{Class III AC의 분포}

Class III AC는 고등식물을 제외한 원생생물, 균류(fungi), 조류(algae), 동물을 포함하는 진핵생물과 원핵생물에서 발견 된다[23,26]. 이 class에 속하는 $\mathrm{AC}$ 들은 활성부위를 구성하는 cyclase homology domain $(\mathrm{CHD})$ 의 아미노산 서열의 유사성 을 갖는다. 대부분의 이 class의 $\mathrm{AC}$ 는 $\mathrm{CHD}$ 를 포함한 복수의 도메인으로 이루어져 있다[23,26]. 이러한 도메인들은 막에 $\mathrm{AC}$ 를 위치시키거나, 신호인지, 그리고 하위 신호전달 분자로 의 신호전달의 기능을 가지고 있다.

포유류에는 두 종류의 $\mathrm{AC}$ 가, 즉 막결합 $\mathrm{AC}$ (membranebound $\mathrm{AC}$ )와 세포질 $\mathrm{AC}$ (soluble $\mathrm{AC}$ ), 존재한다(Fig. 1)[8,20,39]. 막결합 $\mathrm{AC}$ 는 6 개의 a-helix로 구성된 막통과 도메 인(transmembrane domain) 2개와 2개의 CHD로 구성되어 있 다. 발현되는 조직과 활성조절 기작에 따라 9 개의 isoform으로 나뉜다[26,29]. 이러한 형태의 막결합 $\mathrm{AC}$ 는 포유류 뿐만 아니 라 선형동물인 Caenorhabditis elegans와 곤충인 Drosophila melanogaster, 원생생물인 Dictyostelium discoideum 등에서도 발견 된다. 한 polypeptide 내의 두 개의 CHD가 intramolecular dimerization을 통해 한 개의 활성부위를 형성한다(Fig. 2). 포유 류에서 발견되는 세포질 $\mathrm{AC}$ 는 아미노말단에 두 개의 $\mathrm{CHD}$ 를 포함하고 있으며 카복실말단 부위는 자가활성억제 도메인 (autoinhibitory domain)으로 역할을 한다(Fig. 1)[11]. 막결합 $\mathrm{AC}$ 와 마찬가지로 intramolecular dimerization를 통해 한 개

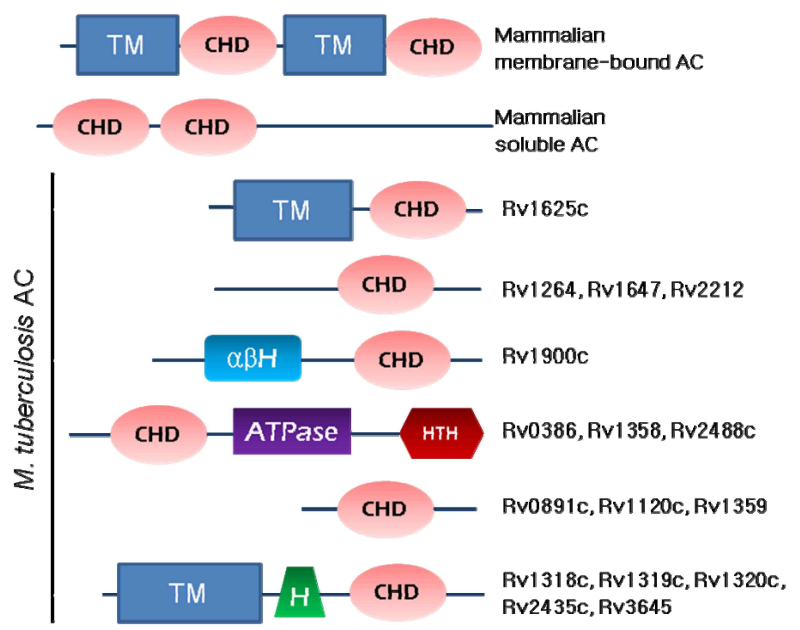

Fig. 1. Domain composition of class III adenylyl cyclases in mammals and mycobacteria. Abbreviations are as follows: CHD, cyclase homology domain; $\alpha \beta \mathrm{H}, \alpha \beta$-hydrolase; ATPase, AAA+ type ATPase; HTH, helix-turn-helix DNA binding domain; H, HAMP-domain; TM, transmembrane domain composed of $\alpha$-helices.

(A)

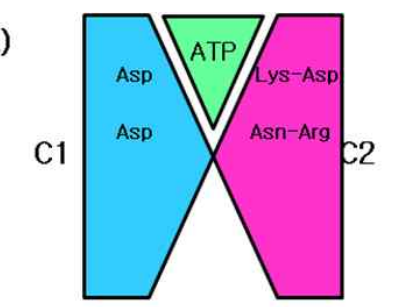

Heterodimeric catalytic domain (mammalian AC)

(B)

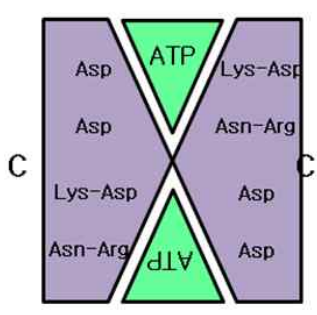

Homodimeric catalytic domain (mycobacterial $\mathrm{AC}$ )

Fig. 2. Schematic structure of the catalytic domain of the class III adenylyl cyclase. (A) The mammalian AC consists of a single polypeptide with two different CHDs (cyclase homology domain: $\mathrm{C} 1$ and $\mathrm{C} 2$ ). Heterodimerization of the two CHDs forms the catalytic domain possessing one active site (ATP-binding site). (B) The polypeptide comprising the mycobacterial $\mathrm{AC}$ contains a single $\mathrm{CHD}$. Homodimerization of two identical CHDs of each polypeptide in a head to tail orientation leads to the formation of the catalytic domain with two active sites. The amino acid residues, which are well conserved among the class III ACs and important for their catalytic activities, are given in the schematic diagrams. 
의 활성부위를 형성한다. 세포질 $\mathrm{AC}$ 와 비슷한 $\mathrm{AC}$ 의 유전자가 원생생물인 Paramecium과 세균인 Chloroflexus aurantiacus의 genome에 존재한다[19].

Saccharomyces cerevisiae에서 발견된 $\mathrm{AC}$ 는 카복실말단은 한 개의 $\mathrm{CHD}$ 를 가지고 아미노말단에는 Ras 결합 도메인을 가지 고 있어 GTP와 결합한 Ras 단백질에 의해 활성화된다[17,18]. Ras 결합 도메인과 CHD 사이에는 14 개의 leucine-rich 도메인 과 protein phosphatase 2c의 촉매 도메인과 유사한 도메인이 위치한다. CHD가 polypeptide에 한 개만이 존재하기 때문에 활성부위를 구성하기 위해서는 두 개의 polypeptide의 dimerization이 일어나야 한다[17]. GTP를 cGMP와 pyrophosphate로 전환시키는 guanylyl cyclase의 구조도 class III AC와 유사하 고 유사한 $\mathrm{CHD}$ 를 포함하고 있음이 밝혀졌다[6].

Mycobacteria에서 발견되는 $\mathrm{AC}$ 는 모두 class III에 속하고 $\mathrm{CHD}$ 를 polypeptide에 한 개만을 가진다(Fig. 1). 따라서 mycobacteria에서 발견되는 $\mathrm{AC}$ 는 homodimer의 4차구조를 가지 며 두 개의 $\mathrm{CHD}$ 가 모여 두 개의 동일한 활성부위를 형성하게 된다(Fig. 2)[35,36].

Class III AC의 촉매 기작

위에서 언급했듯이 class III AC의 활성부위는 두 개의 $\mathrm{CHD}$ 가 서로 반대방향으로(head to tail orientation) 모여서 만나는 지점(interface)에 형성된다. 포유류에서 발견되는 $\mathrm{AC}$ 에서처럼 한 단백질(polypeptide)에 두 개의 CHD가 존재하면 두 개의 $\mathrm{CHD}$ 의 아미노산 서열이 동일하지 않기 때문에 $\mathrm{CHD}$ 가 heterodimer로서 활성부위를 형성한다(Fig. 2A). 이 경우 기질인 ATP가 결합하는 활성부위는 한 개가 형성된다 $[6,23,26]$. S. cerevisiae와 mycobacteria에서 발견되는 $\mathrm{AC}$ 는 단 백질에 한 개의 $\mathrm{CHD}$ 만 존재하므로 활성부위를 형성하기 위 해서는 두 개의 polypeptide가 dimerization이 일어나야 한다 (Fig. 2B). 이 경우는 두 개의 $\mathrm{CHD}$ 가 만나는 지점에 두 개의 활성부위가 형성된다[35]. Class III에 속하는 $\mathrm{AC}$ 는 활성부위 를 형성하는 $\mathrm{CHD}$ 가 비슷한 3 차원 구조를 가지고 있고, 동일 한 촉매 기작을 가지지만 $\mathrm{CHD}$ 의 아미노산 서열의 차이에 따 라 4개의 subgroup으로 나눈다(class IIIa-class IIId)[23].

이 class에 속하는 $\mathrm{AC}$ 의 활성부위에는 일반적으로 6 개의 중요한 아미노산 잔기가 보존되어 있다[23,26]. 촉매에 필요한 금속이온 $\left(\mathrm{Mg}^{2+}\right.$ 또는 $\left.\mathrm{Mn}^{2+}\right)$ 과 결합하는 aspartate-aspartate 잔 기쌍(M. tuberculosis의 Rv1625c에서 Asp-231과 Asp-274), 기 질인 $\mathrm{ATP}$ 과 결합하여 기질특이성을 부여하는 잔기쌍 $\left(M . t u^{-}\right.$ berculosis의 Rv1625c에서 Lys-270과 Asp-339), 그리고 반응 중 에 ATP의 ribose의 3-hydroxyl group이 a-phosphate를 SN2 반응으로 공격해서 $\mathrm{cAMP}$ 를 생성할 때 전이단계(transition state)의 분자를 안정화시키는 asparagine-arginine 잔기쌍 $(M$. tuberculosis의 Rv1625c에서 Asn-346과 Arg-350)이 보존되어 있는 6 개의 아미노산 잔기에 해당한다. Class III AC의 활성에 필수적인 금속이온은 $\mathrm{ATP}$ 의 3 개의 인산기와 결합하여 안정
화시키며 ribose의 3'-hydroxyl group을 a-phosphate에 위치 시키는 것을 돕는다. 전이단계를 안정화시키는 arginine은 ATP의 a-phosphate group의 음(-)전하를 중성화시키며, asparagine은 ribose의 conformation을 반응이 일어날 수 있도 록 안정화시킨다. 활성을 가지는 것으로 증명된 $\mathrm{AC}$ 의 아미노 산 서열을 multiple alignment를 이용하여 비교해 보면 활성 부위에 보존되어 있는 6 개의 잔기 중에 금속이온과 결합하는 두 개의 aspartate 잔기는 필수적으로 보존되어 있다. 전이단 계를 안정화시키는 arginine은 대부분의 $\mathrm{AC}$ 에서 보존되어 있 고, $\mathrm{AC}$ 의 최적 활성을 갖는데 중요한 역할을 함이 증명되었 다. 기질특이성을 부여하는 잔기쌍의 변이는 심한 편이다. 예 를 들어 M. tuberculosis H37Rv의 Rv1318c, Rv1319c, Rv1320c, $\mathrm{Rv} 1358, \mathrm{Rv} 3646$ 에서는 aspartate가 threonine으로 치환되어 있고, Rv0386과 Rv2488c에서는 asparagine으로 보존적으로 치환되어 있다[35]. 또한 기질특이성을 주는 잔기쌍 중 lysine 은 양(+)전하를 띄는 asparagine과 glutamine으로 보존적으로 치환되어 있는 경우도 있다[35].

Class IV, Class V, Class VI

Class I에 속하는 $\mathrm{AC}$ 를 가지는 A. hydrophila와 Y. pestis에는 class I에 속한 $\mathrm{AC}$ 와는 아미노산 서열의 유사성이 없는 또 다 른 $\mathrm{AC}$ 가 발견되었는데, 이것을 class IV로 따로 분류하였다. 이들은 높은 온도 $\left(65^{\circ} \mathrm{C}\right)$ 와 높은 $\mathrm{pH}$ 조건 $(\mathrm{pH}$ 9.5)에 최적화된 생화학적 성질을 지니고 있다[38]. Y. pestis에 존재하는 class $\mathrm{IV} \mathrm{AC}$ 의 3차원 구조가 결정되어 보고되었다[13].

반추동물의 위에서 발견되는 혐기성 세균중 하나인 Prevotella ruminicola D31d에서 E. coli의 cyaA mutant를 complementation하는 유전자가 발견되었다 이 유전자의 산물은 $\mathrm{cAMP}$ 를 생산하는 능력이 있었으나, 지금까지 알려진 $\mathrm{AC}$ 의 아미노산 서열과 유사성을 갖고있지 않아서 class $\mathrm{V}$ 로 따로 분류되었다. 이 $\mathrm{AC}$ 의 분자량은 $67 \mathrm{kDa}$ 으로 혐기성 세균 중 에서는 처음으로 밝혀진 $\mathrm{AC}$ 이다[12].

Class V와 마찬가지로 $\mathrm{AC}$ 유전자가 결손된 E. coll를 이용 해 $\mathrm{AC}$ 활성을 $E$. coli에 부여하는 유전자 $(c y a C)$ 를 질소고정세균 인 Rhizobium etli에서 발견할 수 있었다[40]. $c y a C$ 유전자 역시 이미 알려진 $\mathrm{AC}$ 유전자와는 유사성을 나타내지 않아 class VI 로 새로 분류하였다. 이와 유사한 유전자가 Mesorhizobium loti, Sinorhizobium meliloti, Agrobacterium tumefaciens 등에서 확인 되었지만, 그것에 대한 기능은 아직 밝혀지지 않았다.

\section{Mycobacterial adenylyl cyclase}

Mycobacterium속의 M. marinum에서 31개, M. avium에서 12 개, M. leprae에서 4개, M. smegmatis에서 10개, M. tuberculosis $\mathrm{H} 37 \mathrm{Rv}$ 에서 16 개의 $\mathrm{AC}$ 유전자가 확인되었다[35]. 본 총설에서 는 인간에게 결핵을 일으키는 M. tuberculosis H37Rv에서 발견 
되는 16 개의 $\mathrm{AC}$ 에 대하여 연구된 결과를 다룰 것이다.

\section{Rv1625c}

$r v 1625 c$ 유전자에 의해 인코딩되는 $\mathrm{AC}$ 는 $M$. tuberculosis에 서 가장 먼저 그 특성이 밝혀졌으며, 이 $\mathrm{AC}$ 의 도메인 구성은 카복실말단에 $\mathrm{CHD}$ 가, 아미노말단에는 6 개의 a-helix로 구성 된 막통과 도메인이 존재한다. 이는 6 개의 a-helix로 구성된 2 개의 막통과 도메인과 2 개의 $\mathrm{CHD}$ 를 가지는 포유류의 막결 합 $\mathrm{AC}$ 의 반쪽구조와 동일하다고 볼 수 있다(Fig. 1). Rv1625c 은 포유류 세포 내에서도 $\mathrm{AC}$ 로서 기능을 할 수 있다는 연구결 과가 보고되었다[14,15,30].

\section{Rv1264와 Rv1647}

$\mathrm{Rv} 1264$ 는 카복실말단에 $\mathrm{CHD}$ 하나만을 포함한 단순한 형 태로(Fig. 1), 모든 mycobacteria에서는 이와 동일한 orthologue들이 존재한다. Rv1264의 아미노말단은 자가억제 도메 인으로서 작용한다[22]. 즉, 아미노말단 도메인이 제거되면 $\mathrm{AC}$ 의 활성이 300 배 증가함이 관찰되었다. 또한 $\mathrm{pH}$ 에 따라 효소활성이 달라지는데, holoenzyme 상태일 때 산성인 $\mathrm{pH}$ 6.0 에서 가장 높은 활성이 나타났으며, 정제된 아미노말단이 제거된 $\mathrm{AC}$ 는 $\mathrm{pH} 5.5$ 8.0 범위에서 일정하게 높은 활성이 나 타났다. 그리고 Rv1264의 3차원 구조의 규명과 돌연변이 연구 로부터 아미노말단의 조절 도메인에 있는 10번째 a-helix (a $\mathrm{N} 10$ switch)가 pH에 반응하여 conformation이 변화하여 AC 의 활성이 조절됨이 제안되었다[41].

$\operatorname{Rv} 1647$ 은 Rv1264와 유사한 도메인 구조를 가졌으며 $\mathrm{Rv} 1264$ 와는 반대로 알칼리 $\mathrm{pH}$ 범위 내에서 높은 효소활성이 나타났으며, detergent를 처리 하게 되면 효소활성이 증가됨 이 관찰되었다. 반면에 높은 염 농도 범위에서는 효소활성이 억제되었다[32].

\section{Rv1900c}

$\mathrm{Rv} 1900 \mathrm{c}$ 의 아미노말단에는 약 300 개의 아미노산으로 구성 된 aß-hydrolase 도메인을 포함하는데(Fig. 1), 이 도메인에서 실질적으로 가수분해 활성은 검출하지 못하였다. Rv1900c의 3 차원 구조로부터 이 $\mathrm{AC}$ 는 homodimer의 4 차구조를 가지지 만 2개의 활성부위 중 한 개만이 기능을 함이 밝혀졌다. 즉, homodimerization에 의해 2개의 $\mathrm{CHD}$ 의 interface에 만들어 진 2개의 활성부위 중 하나에만 금속이온과 ATP가 결합되어 있음이 관찰되었다[37]. Rv1900c는 AC 활성의 약 $20 \%$ 정도의 guanylyl cyclase 활성도 가지고 있음이 증명되었다. 진화학적 으로 $\mathrm{CHD}$ 의 homodimerization에 의해 활성부위가 만들어지 는 $\mathrm{AC}$ 와 $\mathrm{CHD}$ 의 heterodimerization에 의해 활성부위가 만들 어지는 $\mathrm{AC}$ 의 중간단계로 생각된다.

\section{Rv0386}

Rv0386은 CHD 옆에 AAA+ATPase 도메인과 helix- turn-helix DNA 결합 도메인이 나란히 나열된 구조로 되어있 다(Fig. 1). 이 $\mathrm{AC}$ 는 $\mathrm{AC}$ 활성 이외에 guanylyl cyclase 활성을 가지고 있다. 그 이유는 Rv0386의 활성부위에는 기질특이성 을 부여하는 lysine-aspartate 잔기쌍 대신 glutamine-asparagine 잔기쌍이 존재하는데, 이 아미노산들이 GTP를 기질로 서 인식하기 때문이다. Glutamine-asparagine 잔기쌍을 원래 의 lysine-aspartate 잔기쌍으로 치환하면 guanylyl cyclase 활 성이 사라짐이 관찰되었다[10,25]. Rv0386은 helix-turn-helix $\mathrm{DNA}$ 결합 도메인이 있음에도 불구하고 세포벽에 붙어있는 것으로 밝혀졌고 결핵균이 대식세포(macrophage)에 감염 시 에 대식세포 내의 $\mathrm{cAMP}$ 의 농도를 크게 증가시키는 $\mathrm{AC}$ 로 규 명되었다. Rv0386 결손은 쥐 모델에서 결핵균의 병원성의 감 소를 일으킨다[2].

\section{Rv1120c}

Rv1120c는 164개의 아미노산만으로 이루어진 class III AC 중 $\mathrm{CHD}$ 만을 갖는 가장 작으면서 단순한 형태이다(Fig. 1). 이 유전자는 frameshift 현상에 의해 pseudogene형태로 존재한 다. 따라서 M. avium TN104에서 Rv1120c와 orthologue인 Ma1120 유전자산물을 바탕으로 Rv1120c의 생화학적 및 효소 학적 특성을 유추할 수 있었다. Ma1120 유전자 산물은 $\mathrm{Mn}^{2+}$ $\mathrm{ATP}$ 존재하에 최고의 활성이 보인다. 포유류의 $\mathrm{AC}$ 활성억제 자로 잘 알려진 P-site 화합물 $\left(2^{\prime}-\mathrm{deoxy}-3^{\prime}-\mathrm{AMP}\right.$ 와 2',5- $\mathrm{di}^{-}$ deoxy-3'-ATP)에 의해서는 효소활성이 억제되는 현상이 관찰 되었다[34].

\section{Rv1318c, Rv1319c, Rv1320c, Rv2435c, Rv3645}

$\mathrm{Rv} 1318 c, \mathrm{Rv} 1319 \mathrm{c}, \mathrm{Rv1320c}, \mathrm{Rv} 2435 \mathrm{c}$ 그리고 Rv3645 유전 자 산물은 공통적으로 HAMP (histidine kinase, adenylyl cyclases, methyl-accepting chemotaxis protein and posphatase) 도메인을 가지고 있다는 특징이 있다(Fig. 1)[35]. 약 50개의 아미노산으로 구성된 HAMP 도메인은 일반적으로 막통과 도 메인과 효과 도메인(effector domain)사이의 linker의 역할을 하며 막통과 도메인에서 인지한 외부 신호를 효과 도메인에 전달하는 역할을 한다. 이들 5 개의 유전자의 아미노산 서열은 아미노말단의 $\mathrm{HAMP}$ 도메인과 막통과 도메인에 비해 $\mathrm{CHD}$ 에 서 가장 높은 유사성을 보이는데, 이는 각각의 $\mathrm{AC}$ 의 신호인지 기작이 상이함을 나타낸다. 실제로 HAMP 도메인은 Rv3645 의 효소활성을 증가시키는 반면 Rv1319c의 활성은 억제시켰 다. 하지만 $\mathrm{HAMP}$ 가 조절 도메인으로서의 어떻게 $\mathrm{AC}$ 의 활성 을 조절하는지에 대한 구체적인 기작은 아직 밝혀지지 않았다 [24]. Rv1318c, Rv1319c, Rv1320c 그리고 Rv3645의 경우는 기 질특이성을 부여하는 lysine-aspartate 잔기쌍이 lysine-threonine으로 치환되어 있으며[35], Rv1319c의 경우 포유류의 세 포질에 존재하는 $\mathrm{AC}$ 와 마찬가지로 bicarbonate 이온 $\left(\mathrm{HCO}_{3}{ }^{-}\right)$ 에 의해 활성이 증가함이 보고되었다[9]. 


\section{Rv2212}

$\operatorname{Rv} 1264$ 와 43\%의 유사성을 보이는 Rv2212는 이미 보고된 $\mathrm{AC}$ 중 촉매속도가 가장 빠르나 ATP에 대한 친화력은 낮다. 불포화지방산은 이 유전자의 기질에 대한 친화력을 증가시켜 $\mathrm{AC}$ 활성을 증가시킨다[1]. 또한 Thermobifida와 Nocardia에서도 이와 유사한 $\mathrm{AC}$ 를 인코딩하는 유전자가 발견이 되었다.

\section{Rv0891c}

$\mathrm{Rv} 0891 \mathrm{c}$ 는 한 개의 $\mathrm{CHD}$ 로 구성된 단순한 형태로(Fig. 1), helix-turn-helix DNA 결합 도메인을 가지는 Rv0386, Rv2488c 그리고 Rv1358과 $\mathrm{CHD}$ 부분에서 $6070 \%$ 정도 유사성을 가진 다. 이 사실로부터 Rv0891c은 이들 $\mathrm{AC}$ 와 유사한 생화학적 특 징을 가질 것으로 예상할 수 있다[35].

\section{cAMP의 mycobacteria에서의 역할}

Mycobacteria에서의 cAMP의 영향은 우선 결핵을 일으키 는 원인균으로서, 결핵균(M. tuberculosis)이 숙주내로 침입하 게 되면, 숙주 대식세포의 phagocytosis 작용에 의해 포식 되 고 phagosome내에 머물게 된다. 숙주는 phagosome 내의 병 원균을 죽이기 위해 다양한 방어기작을 펼치게 되는데, 그 중 하나가 lysosome-phagosome fusion을 들 수 있다. 이것은 lysosome이 phagosome과 결합하게 되면 lysosome 내의 가수 분해 효소와 $\mathrm{H}^{+} \mathrm{ATPase}$ 에 의해 phagosome 내의 세균이 소화 되는 작용을 말한다. 이 과정을 위해 phagosome 막에서 lysosome과 fusion시키는 역할을 하는 phagosomal actin의 조립 과정이 요구되는데, cAMP는 phagosomal actin 조립과정을 억제한다고 알려져 있다[16]. 따라서 phagosome 내의 cAMP 농도가 높아지면 phagosome-lysosome fusion을 억제하여 대 식세포 내의 결핵균의 생존력을 높여준다[16]. 비병원성균인 M. smegmatis의 경우 일단 대식세포에 의해 포식 되면 48시간 이내에 죽어버리는 특징이 있다[3]. 이 밖에도 M. microti 역시 대식세포에 감염되면 대식세포 내의 $\mathrm{cAMP}$ 의 농도가 크게 증 가하며, cAMP가 lysosome-phagosome fusion 과정을 억제한 다고 알려졌으며, M. bovis나 M. leprae의 경우에도 일단 숙주 대식세포 내로 들어가면 일시적으로 대식세포 내의 cAMP량 이 증가된다고 알려졌다[27].

이처럼 $\mathrm{CAMP}$ 는 신호전달 과정에서 중요한 요소로서 역할 을 하기 때문에 $\mathrm{cAMP}$ 가 세포내에 적절한 농도로 유지되는 것 역시 중요하다. Phosphodiesterase (PDE)는 cAMP를 AMP 로 가수분해를 시키면서 세포 내의 $\mathrm{cAMP}$ 농도의 항상성을 조 절한다. mycobacteria에서 $\mathrm{PDE}$ 를 인코딩하는 유전자로는 $M$. tuberculosis H37Rv의 Rv0805 유전자, $M$. avium의 Mb0828 유 전자 그리고 M. leprae의 ML2210 유전자가 알려져 있으며, $M$. smegmatis를 포함한 다른 mycobacteria에서는 아직 PDE 유전 자가 확인되지 않았다. 이는 $\mathrm{PDE}$ 외의 $\mathrm{cAMP}$ 의 세포 외로의 분비등의 다른 기작에 의해 mycobacteria 세포 내의 cAMP
항상성이 조절 될 수도 있다는 사실을 암시한다[33].

최근 M. tuberculosis의 대식세포로의 감염 시에 대식세포 내의 $\mathrm{cAMP}$ 의 농도 증가는 $\mathrm{Rv} 0386 \mathrm{AC}$ 에 의한 것으로 증명되 었으며, 대식세포 내의 cAMP 농도의 증가는 protein kinase A (PKA)-cAMP response element binding protein (CREB) 신호전달 경로를 통해 proinflammatory cytokine인 tumor necrosis factor- $a(\mathrm{TNF}-\mathrm{a})$ 의 합성을 증가시킴이 증명되었다 [2]. 대식세포에 의한 TNF-a의 분비는 폐 조직에 caseous necrosis를 유발하며 딱딱한 조직인 면역세포와 격리된 육아종 (granuloma)의 형성을 유도하여 결핵균의 숙주 내에서 생존 률을 증가시킨다. 따라서 결핵균에 의한 면역세포 내에서의 $\mathrm{cAMP}$ 의 증가는 결핵균의 숙주 내에서의 생존률을 증가시키 게 된다.

\section{감사의 글}

이 논문은 부산대학교 자유과제 학술연구비(2년)에 의해 연 구되었음.

\section{References}

1. Abdel, M. A., I. Tews, J. E. Schultz, and J. U. Linder. 2006. Fatty acid regulation of adenylyl cyclase Rv2212 from Mycobacterium tuberculosis H37Rv. FEBS J. 273, 4219-4228.

2. Agarwal, N., G. Lamichhane, R. Gupta, S. Nolan, and W. R. Bishai. 2009. Cyclic AMP intoxication of macrophages by a Mycobacterium tuberculosis adenylate cyclase. Nature 460, 98-102.

3. Anes, E., P. Peyron, L. Staali, L. Jordao, M. G. Gutierrez, H. Kress, M. Hagedorn, I. Maridonneau-Parini, M. A. Skinner, A. G. Wildeman, S. A. Kalamidas, M. Kuehnel, and G. Griffiths. 2006. Dynamic life and death interactions between Mycobacterium smegmatis and J774 macrophages. Cell Microbiol. 8, 939-960.

4. Antoni, F. A. 2000. Molecular diversity of cyclic AMP signalling. Front Neuroendocrinol. 21, 103-132.

5. Baillie, L. and T. D. Read. 2001. Bacillus anthracis, a bug with attitude! Curr. Opin. Microbiol. 4, 78-81.

6. Baker, D. A. and J. M. Kelly. 2004. Structure, function and evolution of microbial adenylyl and guanylyl cyclases. Mol. Microbiol. 52, 1229-1242.

7. Botsford, J. L. and J. G. Harman. 1992. Cyclic AMP in prokaryotes. Microbiol. Rev. 56, 100-122.

8. Buck, J., M. L. Sinclair, L. Schapal, M. J. Cann, and L. R. Levin. 1999. Cytosolic adenylyl cyclase defines unique signaling molecule in mammals. Proc. Natl. Acad. Sci. USA 96, 79-84.

9. Cann, M. J., A. Hammer, J. Zhou, and T. Kanacher. 2003. A defined subset of adenylyl cyclases is regulated by bicarbonate ion. J. Biol. Chem. 278, 35033-35038.

10. Castro, L. I., C. Hermsen, J. E. Schultz, and J. U. Linder. 
2005. Adenylyl cyclase Rv0386 from Mycobacterium tuberculosis H37Rv uses a novel mode for substrate selection. FEBS J. 272, 3085-3092.

11. Chaloupka, J. A., S. A. Bullock, V. Iourgento, L. R. Levin, and J. Buck. 2006. Autoinhibitory regulation of soluble adenylyl cyclase. Mol. Reprod. Dev. 73, 361-368.

12. Cotta, M. A., T. R. Whitehead, and M. B. Wheeler. 1998. Identification of a novel adenylate cyclase in the ruminal anaerobe, Prevotella ruminicola D31d. FEMS Microbiol. Lett. 164, 257-260.

13. Gallagher, D. T., N. N. Smith, S. K. Kim, A. Heroux, H. Robinson, and P. T. Reddy. 2006. Structure of the class IV adenylyl cyclase reveals a novel fold. J. Mol. Biol. 362, 114-122.

14. Guo, Y. L., U. Kurz, A. Schultz, J. U. Linder, D. Dittrich, C. Keller, S. Ehlers, P. Sander, and J. E. Schultz. 2005. Interaction of Rv1625c, a mycobacterial class IIIa adenylyl cyclase, with a mammalian congener. Mol. Microbiol. 57, 667-677.

15. Guo, Y. L., T. Seebacher, U. Kurz, J. U. Linder, and J. E. Schultz. 2001. Adenylyl cyclase Rv1625c of Mycobacterium tuberculosis: a progenitor of mammalian adenylyl cyclases. EMBO J. 20, 3667-3675.

16. Kalamidas, S. A., M. P. Kuehnel, P. Peyron, V. Rybin, S. Rauch, O. B. Kotoulas, M. Houslay, B. A. Hemmings, M. G. Gutierrez, E. Anes, and G. Griffiths. 2006. cAMP synthesis and degradation by phagosomes regulate actin assembly and fusion events: consequences for mycobacteria. J. Cell Sci. 119, 3686-3694.

17. Kataoka, T., D. Broek, and M. Wigler. 1985. DNA sequence and characterization of the Sachharomyces cerevisiae gene encoding adenylate cyclase. Cell 43, 493-505.

18. Kido, M., F. Shima, T. Satoh, T. Asato, K. Kariya, and T. Kataoka. 2002. Critical function of the Ras-associating domain as a primary Ras-binding site for regulation of Saccharomyces cerevisiae adenylyl cyclase. J. Biol. Chem. 277, 3117-3123.

19. Kobayashi, M., J. Buck, and L. R. Levin. 2004. Conservation of functional domain structure in bicarbonate-regulated soluble adenylyl cyclases in bacteria and eukaryotes. Dev. Genes Evol. 214, 503-509.

20. Krupinski, J., F. Coussen, H. A. Bakalyar, W. J. Tang, P. G. Feinstein, K. Orth, C. Slaughter, R. R. Reed, and A. G. Gilman. 1989. Adenylyl cyclase amino acid sequence: possible channel- or transporter-like structure. Science 244, 1558-1564.

21. Ladant, D. and A. Ullmann. 1999. Bordetella pertussis adenylate cyclase: a toxin with multiple talents. Trends Microbiol. 7, 172-176.

22. Linder, J. U., A. Schultz, and J. E. Schultz. 2002. Adenylyl cyclase Rv1264 from Mycobacterium tuberculosis has an autoinhibitory N-terminal domain. J. Biol. Chem. 277, 15271-15276.

23. Linder, J. U. and J. E. Schultz. 2003. The class III adenylyl cyclases: multi-purpose signalling modules. Cell Signal. 15, 1081-1089.
24. Linder, J. U., A. Hammer, and J. E. Schultz. 2004. The effect of HAMP domains on class IIIb adenylyl cyclases from Mycobacterium tuberculosis. Eur. J. Biochem. 271, 2446-2451.

25. Linder, J. U. 2005. Substrate selection by class III adenylyl cyclases and guanylyl cyclases. IUBMB Life 57, 797-803.

26. Linder, J. U. 2006. Class III adenylyl cyclases: molecular mechanisms of catalysis and regulation. Cell Mol. Life Sci. 63, 1736-1751.

27. Lowrie, D. B., V. R. Aber, and P. S. Jackett. 1979. Phagosome-lysosome fusion and cyclic adenosine $3^{\prime}: 5^{\prime}$-monophosphate in macrophages infected with Mycobacterium microti, Mycobacterium bovis BCG or Mycobacterium lepraemurium. J. Gen. Microbiol. 110, 431-441.

28. Mock, M., E. Labruyère, P. Glaser, A. Danchin, and A. Ullmann. 1988. Cloning and expression of the calmodulin-sensitive Bacillus anthracis adenylate cyclase in Escherichia coli. Gene 64, 277-284.

29. Patel, T. B., Z. Du, S. Pierre, L. Cartin, and K. Scholich. 2001. Molecular biological approaches to unravel adenylyl cyclase signaling and function. Gene 269, 13-25.

30. Reddy, S. K., M. Kamireddi, K. Dhanireddy, L. Young, A. Davis, and P. T. Reddy. 2001. Eukaryotic-like adenylyl cyclases in Mycobacterium tuberculosis H37Rv: cloning and characterization. J. Biol. Chem. 276, 35141-35149.

31. Roy, A., A. Danchin, E. Joseph, and A. Ullmann. 1983. Two functional domains in adenylate cyclase of Escherichia coli. J. Mol. Biol. 165, 197-202.

32. Shenoy, A. R., N. P. Sreenath, M. Mahalingam, and S. S. Visweswariah. 2005. Characterization of phylogenetically distant members of the adenylate cyclase family from mycobacteria: Rv1647 from Mycobacterium tuberculosis and its orthologue ML1399 from M. leprae. Biochem. J. 387, 541-551.

33. Shenoy, A. R., N. Sreenath, M. Podobnik, M. Kovacevic, and S. S. Visweswariah. 2005. The Rv0805 gene from Mycobacterium tuberculosis encodes a $3^{\prime}, 5^{\prime}$-cyclic nucleotide phosphodiesterase: biochemical and mutational analysis. Biochemistry 44, 15695-15704.

34. Shenoy, A. R., A. Srinivas, M. Mahalingam, and S. S. Visweswariah. 2005. An adenylyl cyclase pseudogene in Mycobacterium tuberculosis has a functional ortholog in Mycobacterium avium. Biochimie 87, 557-563.

35. Shenoy, A. R. and S. S. Visweswariah. 2006. Mycobacterial adenylyl cyclases: biochemical diversity and structural plasticity. FEBS Lett. 580, 3344-3352.

36. Shenoy, A. R. and S. S. Visweswariah. 2006. New messages from old messengers: cAMP and mycobacteria. Trends Microbiol. 14, 543-550.

37. Sinha, S. C., M. Wetterer, S. R. Sprang, J. E. Schultz, and J. U. Linder. 2005. Origin of asymmetry in adenylyl cyclases: structures of Mycobacterium tuberculosis Rv1900c. EMBO J. 24, 663-673.

38. Sismeiro, O., P. Trotot, F. Biville, C. Vivares, and A. Danchin. 1998. Aeromonas hydrophila adenylyl cyclase 2: a new class of adenylyl cyclases with thermophilic properties and $\mathrm{se}^{-}$ quence similarities to proteins from hyperthermophilic archaebacteria. J. Bacteriol. 180, 3339-3344. 
39. Sunahara, R. K. and R. Taussig. 2002. Isoforms of mammalian adenylyl cyclase: multiplicities of signaling. Mol. Interv. $2,168-184$.

40. Téllez-Sosa, J., N. Soberón, A. Vega-Segura, M. E. Torres-Márquez, and M. A. Cevallos. 2002. The Rhizobium etli cyaC product: characterization of a novel adenylate $\mathrm{cy}^{-}$ clase class. J. Bacteriol. 184, 3560-3568.

41. Tews, I., F. Findeisen, I. Sinning, A. Schultz, J. E. Schultz, and J. U. Linder. 2005. The structure of a $\mathrm{pH}^{-}$-sensing mycobacterial adenylyl cyclase holoenzyme. Science 308, 1020-1023.

42. Yahr, T. L., A. J. Vallis, M. K. Hancock, J. T. Barbieri, D. W. Frank, and Y. Exo. 1998. An adenylate cyclase secreted by the Pseudomonas aeruginosa type III system. Proc. Natl. Acad. Sci. USA 95, 13899-13904.

초록 : 마이코박테리아의 adenylyl cyclase

전한승 ${ }^{1}$. 고인정 ${ }^{2} \cdot{\text { 오정일 }{ }^{1} \star}^{1}$

( ${ }^{1}$ 부산대학교 미생물학과, ${ }^{2} \mathrm{KAIST}$ 부설 한국과학영재학교 $)$

Adenylyl cyclase (AC)는 ATP로부터 cAMP를 형성하는 반응을 촉매한다. AC에 의해 생산된 cAMP는 다양한 신호전달 경로에서 이차전달자로 사용되고 많은 종에서 다양한 세포기능을 조절한다. $\mathrm{AC}$ 는 1 차구조에 따라 6 개 의 그룹으로 나눌 수 있다. 진핵생물과 Mycobacterium 속에 속하는 세균에서는 class III에 속하는 AC만이 발견된 다. Class III에 속하는 AC의 경우 catalytic cyclase 도메인이 dimer를 형성해야만 활성부위가 형성되고 활성을 가지게 된다. 포유류의 $\mathrm{AC}$ 는 하나의 polypeptide에 2개의 catalytic cyclase 도메인을 가지고 있고, 이 두 개의 도메인이 intramolecular dimerization을 통해서 활성부위를 형성한다. 반면에 mycobacteria의 AC는 polypeptide 에 한 개의 catalytic cyclase 도메인을 가지고 있고, homodimer의 4차구조를 형성하여 활성을 가지게 된다. Class $\mathrm{III} \mathrm{AC}$ 의 활성을 위해서 필요한 6 개의 아미노산 잔기가 활성부위에 잘 보존되어 있다. 이 6 개의 아미노산 잔기는 $\mathrm{Mg}^{2+}$ 과 결합을 하는 2개의 aspartate 잔기쌍, 기질특이성을 부여하는 lysine-aspartate 잔기쌍, 그리고 반응 전이상 태를 안정화시키는 arginine-asparagine 잔기쌍들로 이루어져 있다. Mycobacterium tuberculosis H37Rv에서는 16개 의 $\mathrm{AC}$ 유전자가 발견되었으며, 이 $\mathrm{AC}$ 의 연구된 특성에 대해 본 총설에서 다룰 것이다. 